\title{
Review \\ Modern Clinical Research on LSD
}

\author{
Matthias E Liechti*,1,2,3 \\ 'Psychopharmacology Research, Clinical Pharmacology and Toxicology, Department of Biomedicine, University Hospital Basel, University of Basel, \\ Basel, Switzerland; ${ }^{2}$ Psychopharmacology Research, Clinical Pharmacology and Toxicology, Department of Clinical Research, University Hospital \\ Basel, University of Basel, Basel, Switzerland; ${ }^{3}$ Psychopharmacology Research, Clinical Pharmacology and Toxicology, Department of Internal \\ Medicine, University Hospital Basel, University of Basel, Basel, Switzerland
}

\begin{abstract}
All modern clinical studies using the classic hallucinogen lysergic acid diethylamide (LSD) in healthy subjects or patients in the last 25 years are reviewed herein. There were five recent studies in healthy participants and one in patients. In a controlled setting, LSD acutely induced bliss, audiovisual synesthesia, altered meaning of perceptions, derealization, depersonalization, and mystical experiences. These subjective effects of LSD were mediated by the $5-\mathrm{HT}_{2 \mathrm{~A}}$ receptor. LSD increased feelings of closeness to others, openness, trust, and suggestibility. LSD impaired the recognition of sad and fearful faces, reduced left amygdala reactivity to fearful faces, and enhanced emotional empathy. LSD increased the emotional response to music and the meaning of music. LSD acutely produced deficits in sensorimotor gating, similar to observations in schizophrenia. LSD had weak autonomic stimulant effects and elevated plasma cortisol, prolactin, and oxytocin levels. Resting-state functional magnetic resonance studies showed that LSD acutely reduced the integrity of functional brain networks and increased connectivity between networks that normally are more dissociated. LSD increased functional thalamocortical connectivity and functional connectivity of the primary visual cortex with other brain areas. The latter effect was correlated with subjective hallucinations. LSD acutely induced global increases in brain entropy that were associated with greater trait openness 14 days later. In patients with anxiety associated with life-threatening disease, anxiety was reduced for 2 months after two doses of LSD. In medical settings, no complications of LSD administration were observed. These data should contribute to further investigations of the therapeutic potential of LSD in psychiatry.

Neuropsychopharmacology (2017) 42, 2 II4-2127; doi:I0.1038/npp.2017.86; published online 14 June 2017
\end{abstract}

\section{INTRODUCTION}

The present article reviews studies on the clinical pharmacology and use of lysergic acid diethylamide (LSD) in psychiatry research, with a focus on recent clinical studies. Older studies that were published in the 1950s-1970s before the prohibition of LSD are summarized elsewhere (Passie et al, 2008). All modern controlled clinical studies of LSD published in the past 25 years were included in the present review based on medline and clinicaltrials.gov database searches. Other authors have reviewed serotonergic hallucinogens, including LSD (Dos Santos et al, 2016; Nichols, 2016; Passie et al, 2008), but did not cover the recent experimental clinical LSD research.

\section{HISTORY}

LSD was first synthesized in 1938, and its psychoactive properties were discovered in 1943. The similarity between the subjective psychotomimetic effects of LSD and

*Correspondence: Professor ME Liechti, Psychopharmacology Research, Clinical Pharmacology and Toxicology, Department of Biomedicine, University Hospital Basel, University of Basel, Schanzenstrasse 55, Basel CH-4056, Switzerland. Tel: +4I 6I 32868 68, Fax: +4I 6I 265 45 60, E-mail: matthias.liechti@usb.ch

Received 6 February 2017; revised 19 April 2017; accepted 20 April 2017; accepted article preview online 27 April 2017 schizophrenia were noted in 1947 , leading to the experimental use of LSD to model psychosis. From 1949 to 1966, LSD (Delysid, LSD 25) was provided to psychiatrists and researchers to gain insights into the world of mental patients' and to assist psychotherapy. In the 1950s-1960s, LSD and LSD-associated psychotherapy were investigated with regard to anxiety associated with terminal cancer, alcoholism, opioid use disorder, and depression (Passie et al, 2008). LSD is a well-studied pharmacological substance, with more than 1000 published reports (Nichols, 2016). LSD has been an important tool in neuroscience and drug development (Nichols, 2016) and has influenced the arts and society. Clinical research on LSD came to a halt in the early 1970s because of political pressure following its widespread uncontrolled use. Nevertheless, the recreational use of LSD has remained high. In 2010, an estimated 32 million US residents reported lifetime use of LSD (Krebs and Johansen, 2013). In the 1990s, clinical hallucinogen research very slowly began again with experimental studies of psilocybin and dimethyltryptamine (DMT) (Gouzoulis-Mayfrank et al, 2005; Strassman and Qualls, 1994a; Strassman et al, 1994b). The first modern research findings from studies of LSD (Gasser et al, 2014, 2015), psilocybin (Carhart-Harris et al, 2016a; Griffiths et al, 2016; Grob et al, 2011; Johnson et al, 2014; Ross et al, 2016), and ayahuasca (which contains DMT) (Osorio et al, 2015) in psychiatric patients have only very recently been published. Legally authorized LSD- 
Table I Receptor Interaction Profiles for LSD and Other Classic Serotonergic Hallucinogens at Human Receptors

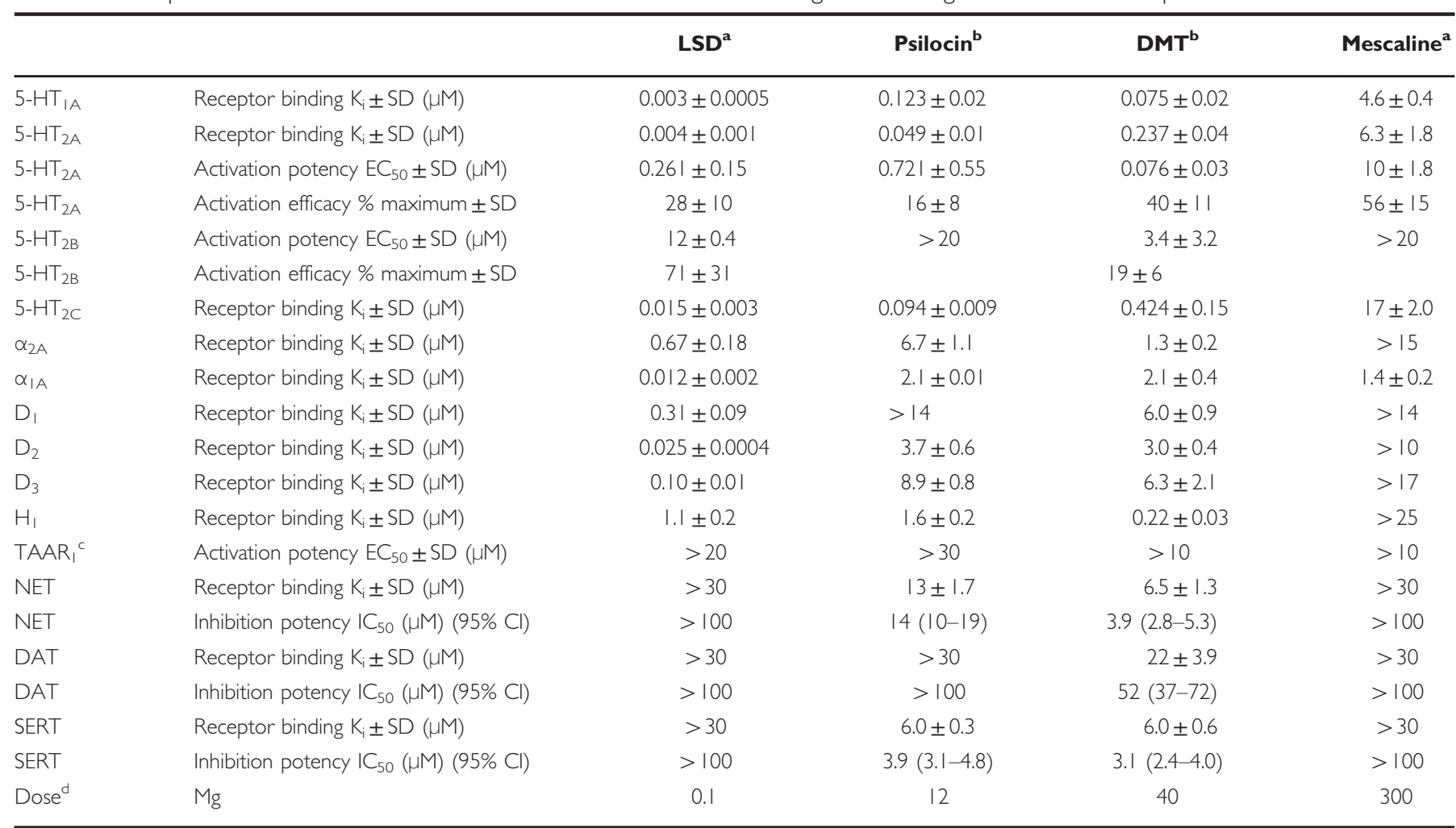

Abbreviations: DAT, dopamine transporter; NET, norepinephrine transporter; SERT, serotonin transporter.

All data were generated using the same assays across substances to allow for direct comparisons.

${ }^{a}$ Rickli et al, 2015.

${ }^{\mathrm{b}}$ Rickli et al, 2016.

'Simmler et al, 2016.

dEstimated average psychoactive dose in humans from Passie et al, 2008 and Nichols, 2004.

assisted psychotherapy is currently offered to very few patients in Switzerland in the context of compassionate use and based on case-by-case authorizations by the Federal Health Office. In addition, experimental research on LSD in healthy subjects has gained new momentum and resulted in novel findings, which are reviewed herein.

\section{RECEPTOR INTERACTION PROFILE AND MECHAN- ISM OF ACTION}

Serotonergic hallucinogens can be classified based on their chemical structure as phenethylamines and tryptamines. Within the tryptamines, there are the simple tryptamines including the classic natural hallucinogens psilocybin (the prodrug for psilocin), DMT, and mescaline and the ergolines including mainly LSD. Table 1 shows the human receptor interaction profile for LSD compared with that of other classic serotonergic hallucinogens obtained with the same assays (Table 1). LSD potently binds to human serotonin (5-hydroxytryptamine (5-HT)) 5- $\mathrm{HT}_{1 \mathrm{~A}}, 5-\mathrm{HT}_{2 \mathrm{~A}}, 5-\mathrm{HT}_{2 \mathrm{C}}$, dopamine $\mathrm{D}_{2}$, and $\alpha_{2}$ adrenergic receptors and less potently to $\alpha_{1}$ adrenergic, $\mathrm{D}_{1}$, and $\mathrm{D}_{3}$ receptors (Rickli et al, 2015, 2016) (Table 1). LSD also activates rat and mouse trace amine-associated receptor $1\left(\mathrm{TAAR}_{1}\right)$ but not human TAAR 1 (Simmler et al, 2016). LSD is a partial agonist at $5-\mathrm{HT}_{2 \mathrm{~A}}$ receptors (Rickli et al, 2016) (Table 1). 5- $\mathrm{HT}_{2 \mathrm{~A}}$ receptors primarily mediate the hallucinogenic effects of LSD (Nichols, 2016; Preller et al, 2017; Vollenweider et al, 1998; Kraehenmann et al, 2017). The affinity of hallucinogens for $5-\mathrm{HT}_{2 \mathrm{~A}}$ receptors but not $5-\mathrm{HT}_{1 \mathrm{~A}}$ receptors is correlated with psychoactive potency in humans. Although the subjective effects of LSD in humans can be blocked by pretreatment with a 5- $\mathrm{HT}_{2 \mathrm{~A}}$ receptor antagonist (Preller et al, 2017; Kraehenmann et al, 2017) and are therefore clearly mediated by $5-\mathrm{HT}_{2 \mathrm{~A}}$ receptor activation, the signaling pathways and downstream effects that mediate the effects of LSD have not been conclusively identified (Nichols, 2016). A key mechanism of action of LSD and other serotonergic hallucinogens is the activation of frontal cortex glutamate transmission secondary to $5-\mathrm{HT}_{2 \mathrm{~A}}$ receptor stimulation. However, interactions between the 5-HT and glutamate systems are unclear (Nichols, 2016). Increases in glutamatergic activity in the prefrontal cortex may result in downstream modulatory effects in subcortical areas and alterations in the gating functions of sensory and cognitive processing. Some notable differences can be seen between the pharmacological profiles of LSD and other serotonergic hallucinogens. First, LSD more potently binds $5-\mathrm{HT}_{2 \mathrm{~A}}$ receptors than psilocybin, mescaline, and DMT (Rickli et al, 2016) (Table 1). Second, LSD is more potent at $5-\mathrm{HT}_{1}$ receptors (Rickli et al, 2016), which may contribute to the effects of hallucinogens. However, there are no studies on the role of the $5-\mathrm{HT}_{1}$ 
receptor in the effects of LSD in humans. Third, LSD binds adrenergic and dopaminergic receptors at submicromolar concentrations, which is not the case for other classic serotonergic hallucinogens (Rickli et al, 2016) (Table 1). In animals, dopamine $\mathrm{D}_{2}$ receptors were shown to contribute to the discriminative stimulus effects of LSD in the late phase of the acute response (Marona-Lewicka and Nichols, 2007). In humans, LSD may indirectly enhance dopamine neurotransmission (Nichols, 2016), with no role of direct $\mathrm{D}_{2}$ receptor stimulation (Preller et al, 2017; Kraehenmann et al, 2017). Serotonergic hallucinogens presumably produce overall similar acute subjective (Hollister and Hartman, 1962; Wolbach et al, 1962) and potential therapeutic effects in humans. The early clinical trials used mostly LSD while most of the recent hallucinogen studies used psilocybin because of its ease of use due to the shorter action and less controversial history (Nichols et al, 2017; Nutt, 2016). However, modern studies need to directly investigate whether the effects of LSD in humans differ qualitatively from those of psilocybin and DMT, notwithstanding LSD's longer duration of action.

\section{STUDIES IN HEALTHY SUBJECTS}

Five novel experimental placebo-controlled studies have been conducted in Basel, London, and Zurich in a total of 95 normal subjects (Table 2). All studies used a crossover design and were placebo-controlled. The Basel and Zurich studies were randomized and double-blind, whereas the London studies were non-randomized and single-blind. Low-moderate doses of LSD base of 40-80 $\mu$ g intravenously (London) or $100 \mu \mathrm{g}$ orally (Basel and Zurich) were used in studies including brain imaging and a relatively high dose of $200 \mu \mathrm{g}$ LSD base was used in one study in Basel without brain imaging. A full LSD reaction is expected at doses of 100-200 $\mu \mathrm{g}$ (Pahnke et al, 1969; Passie et al, 2008). Similar and higher doses of LSD were used in patients in the 1950s-1970s (Krebs and Johansen, 2012; Pahnke et al, 1970).

\section{Subjective Effects}

Modern placebo-controlled studies using validated psychometric scales have only recently been conducted (CarhartHarris et al, 2016b; Kraehenmann et al, 2017; Preller et al, 2017; Schmid et al, 2015). In a controlled setting, the subjective effects of LSD were predominantly positive (Dolder et al, 2016; Schmid et al, 2015). Mean group ratings of 'good drug effect' and 'drug liking' on visual analog scales (VASs) reached $90 \%$ of maximal possible VAS scores after administration of $200 \mu \mathrm{g}$ LSD (Schmid et al, 2015). In contrast, LSD produced only small $(<25 \%)$ mean group increases in 'negative drug effect' and 'fear' (Dolder et al, 2017; Schmid et al, 2015). However, transiently greater ratings of negative drug effects $(>50 \%)$ are seen in approximately half of the subjects at a $200 \mu \mathrm{g}$ dose of LSD (Dolder et al, 2017). Thus, within a session all subjects experience positive drug effects but some also negative drug effects. Profound anxiety or panic was not experienced, and pharmacological sedation was not needed (Dolder et al, 2016; Schmid et al, 2015). LSD increased ratings on all dimensions and subscales of the 5-dimension altered states of consciousness (5D-ASC) scale that has been used in all modern studies
(Carhart-Harris et al, 2016b; Kraehenmann et al, 2017; Liechti et al, 2017; Preller et al, 2017; Schmid et al, 2015) (Figure 1). LSD mainly induced a blissful state, audiovisual synesthesia, changes in the meaning of perceptions, and positively experienced derealization and depersonalization (Carhart-Harris et al, 2016b; Liechti et al, 2017; Schmid et al, 2015). An oral dose of $200 \mu \mathrm{g}$ LSD produced significantly greater bliss, changes in the meaning of perceptions, and insightfulness compared with $100 \mu \mathrm{g}$ (Liechti et al, 2017). Intravenous LSD at a dose of $75 \mu \mathrm{g}$ (Carhart-Harris et al, 2016b) produced similar ratings on the 5D-ASC as an oral dose of $100 \mu \mathrm{g}$ (Liechti et al, 2017) but lower ratings compared with an oral dose of $200 \mu \mathrm{g}$ (Schmid et al, 2015) (Figure 1). Pretreatment with the $5-\mathrm{HT}_{2 \mathrm{~A}}$ receptor antagonist ketanserin fully prevented the effects of $100 \mu \mathrm{g}$ LSD on the 5D-ASC (Kraehenmann et al, 2017; Preller et al, 2017), indicating that the mind-altering effects of LSD in humans are primarily mediated by $5-\mathrm{HT}_{2 \mathrm{~A}}$ receptors. LSD elicited spontaneous synesthesia-like experiences (Carhart-Harris et al, 2016b; Liechti et al, 2017; Preller et al, 2017; Schmid et al, 2015), but it did not induce more vivid color experiences in response to grapheme or sound stimuli (Terhune et al, 2016). These findings indicate that LSD alters spontaneous processes rather than induced responses (Terhune et $a l, 2016)$. LSD at $40-80 \mu$ g, i.v., increased suggestibility (vividness of imagination) but not cued imagery (Carhart-Harris et al, 2015). LSD at $200 \mu \mathrm{g}$, p.o. acutely induced mystical experiences in healthy subjects and patients during LSD-assisted psychotherapy (Liechti et al, 2017). Studies of psilocybin showed that greater acute mystical experiences were significantly associated with positive long-term effects on mood and personality in healthy subjects (Griffiths et al, 2011) and better therapeutic outcomes in patients with anxiety, depression, and substance use disorder (Garcia-Romeu et al, 2015; Griffiths et al, 2011, 2016; Ross et al, 2016). Thus, acute substance-induced mystical-type effects during therapeutic sessions appear to predict the long-term effects of hallucinogens. However, LSD-induced mystical-type effects were highly correlated with other alterations of consciousness and particularly the blissful state on the 5D-ASC (Liechti et al, 2017), indicating that greater positive acute responses to hallucinogens and not specifically mystical-type effects may generally be associated with any better long-term effects on mood. Furthermore, LSD increased feelings of well-being, happiness, closeness to others, openness, and trust (Dolder et al, 2016; Schmid et al, 2015). Such empathogenic effects on mood are typically produced by 3,4-methylenedioxymethamphetamine (MDMA; ecstasy) (Hysek et al, 2014a) and may facilitate psychotherapy. A $200 \mu \mathrm{g}$ dose of LSD produced greater feelings of closeness to others, happiness, openness, and trust than a $100 \mu \mathrm{g}$ dose (Dolder et al, 2016). Consistently, an LSD dose of $200 \mu \mathrm{g}$ is currently used in LSD-assisted psychotherapy in Switzerland (Gasser et al, 2014, 2015).

No differences in subjective VAS-rated responses to LSD were found between subjects with no prior hallucinogen use and subjects with moderate experience (1-3 prior uses) (Schmid et al, 2015). The effects of LSD on the 5D-ASC were also similar between subjects with no prior hallucinogen use $(n=21)$ (Dolder et al, 2016) and subjects who had used LSD $14 \pm 18$ times (mean \pm SD) (Carhart-Harris et al, 2016b). No correlations were found between past LSD use and the acute 
Table 2 Modern Clinical Placebo-Controlled LSD Studies

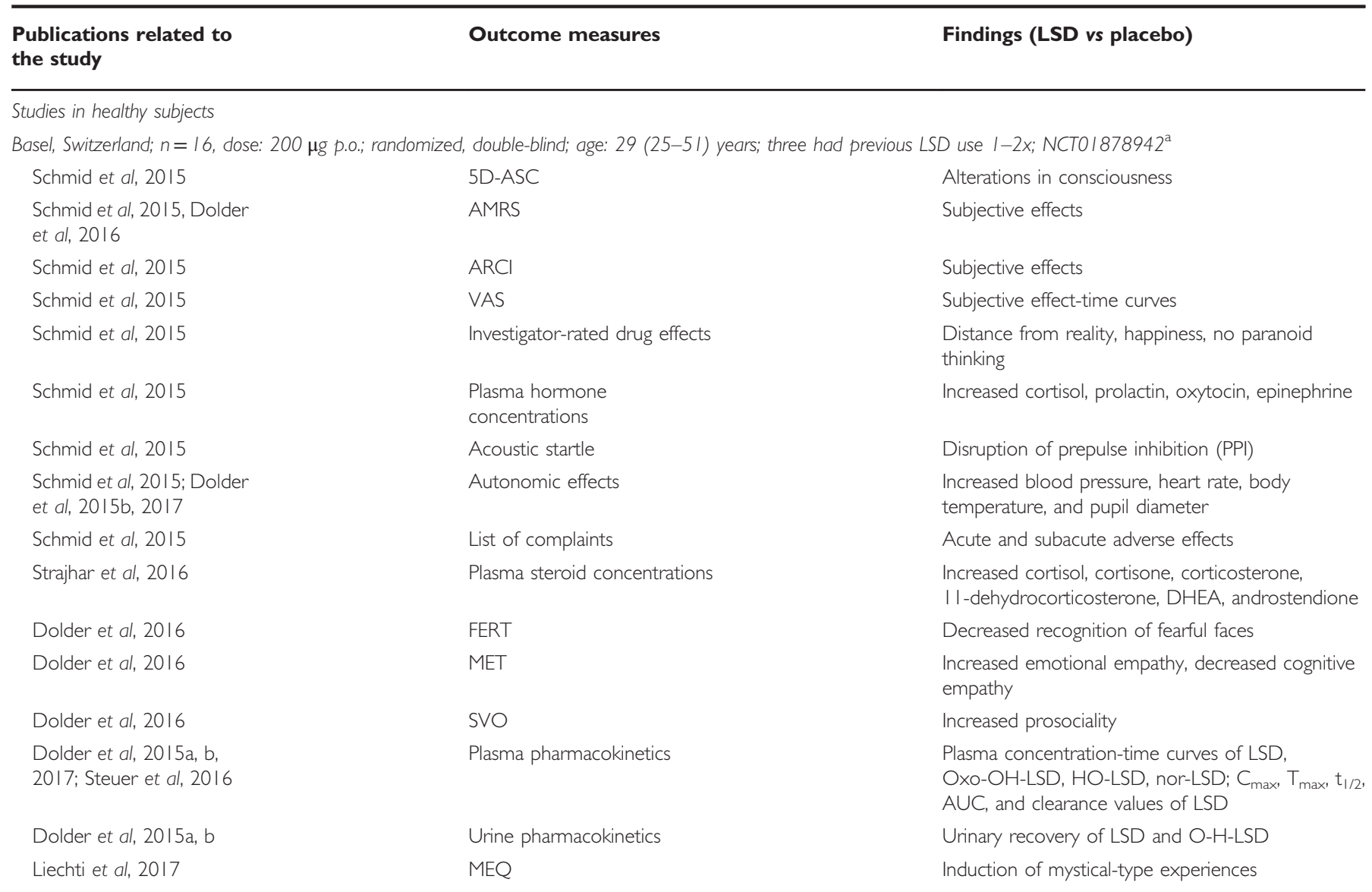

Basel, Switzerland; $n=24$, dose: 100 pg p.o.; randomized, double-blind; age: 33 (25-60) years; 3 had previous LSD use Ix; NCT02308969a

\begin{tabular}{|c|c|c|}
\hline Liechti et al, 2017 & 5D-ASC & Alterations in consciousness and dose response \\
\hline Dolder et al, 2016 & AMRS & Subjective effects and dose response \\
\hline Dolder et al, 2016 & VAS & Subjective effect-time curves and dose response \\
\hline Dolder et al, 2016 & FERT & Decreased recognition of fearful and sad faces \\
\hline Dolder et al, 2016 & MET & $\begin{array}{l}\text { Trend-increase in emotional empathy, decreased } \\
\text { cognitive empathy }\end{array}$ \\
\hline Dolder et al, 2016 & SVO & Prosocial orientation increased \\
\hline Dolder et al, 2016, 2017 & Autonomic effects & $\begin{array}{l}\text { Increased blood pressure, heart rate, body } \\
\text { temperature, and pupil diameter }\end{array}$ \\
\hline Mueller et al, 2017a & $\begin{array}{l}\text { BOLD response to fearful faces } \\
(n=20)\end{array}$ & Reduced left amygdala reactivity \\
\hline Mueller et al, 20I7b & rsfMRI $(n=20)$ & Increased thalamocortical connectivity \\
\hline Schmidt et al, 2017 & $\begin{array}{l}\text { BOLD response during } \mathrm{GO} / \\
\mathrm{NO}-\mathrm{Go}(n=18)\end{array}$ & $\begin{array}{l}\text { Impaired inhibitory performance and altered } \\
\text { parahippocampal activation }\end{array}$ \\
\hline
\end{tabular}

London, UK; $n=10$, Dose 40-80 $\mu \mathrm{g}$ i.v.; non-randomized, single-blind; age 34 (26-47) years; mean previous LSD use: 65x (0-250x)

Carhart-Harris et al, 2015

Carhart-Harris et al, 2015

Kaelen et al, 2015

Terhune et al, 2016
CIS

MIT

Geneva emotional music scale

Grapheme/sound-color associations
Increased vividness/realism of imagination No change in vividness of mental imagery Increased emotional response to music No effect on synesthesia in response to stimuli

London, UK; $n=20$; dose 75 g i.v.; non-randomized, single-blind; age 31 (22-47) years, mean previous LSD use: I4x (0-70x)

$\begin{array}{ll}\text { Carhart-Harris et al, 2016b } & \text { 5D-ASC } \\ \text { Carhart-Harris et al, 2016b } & \text { PSI }\end{array}$

Carhart-Harris et al, $2016 \mathrm{~b}$
Alterations in consciousness

Cognitive disorganization, delusion, paranoia 
Table 2 Continued

\begin{tabular}{|c|c|c|}
\hline $\begin{array}{l}\text { Publications related to } \\
\text { the study }\end{array}$ & Outcome measures & Findings (LSD vs placebo) \\
\hline Carhart-Harris et al, 2016b & Effects after 14 days & Increased optimism and trait openness \\
\hline Kaelen et al, 2016 & $\begin{array}{l}\text { rsfMRI with/without music } \\
(n=12)\end{array}$ & $\begin{array}{l}\text { Interaction of music and LSD on parahipocampal- } \\
\text { visual cortex functional connectivity }\end{array}$ \\
\hline Lebedev et al, 2016 & $\begin{array}{l}\text { rsfMRI with/without music } \\
(n=12)\end{array}$ & $\begin{array}{l}\text { Acutely increased entropy predicts trait openness } \\
\text { I } 4 \text { days later }\end{array}$ \\
\hline Carhart-Harris et al, $2016 \mathrm{c}$ & rsfMRI, ASL, MEG $(n=15)$ & $\begin{array}{l}\text { Increased blood flow and alpha power in visual } \\
\text { cortex, visual cortex connectivity correlates with } \\
\text { hallucinations, decreased parahippocampus- } \\
\text { retrosplenial cortex connectivity correlates with } \\
\text { ego-dissolution }\end{array}$ \\
\hline Roseman et al, 2016 & rsfMRI $(n=10)$ & $\begin{array}{l}\text { Early visual cortex activity with eyes-closed more } \\
\text { similar to seeing visual inputs }\end{array}$ \\
\hline Tagliazucchi et al, 2016 & rsfMRI, ego-dissolution & Increased global connectivity \\
\hline Speth et al, 2016 & $\begin{array}{l}\text { rsfMRI, linguistic references } \\
(n=15) \text { to mental spaces for } \\
\text { the past, present and future }\end{array}$ & $\begin{array}{l}\text { Fewer mental spaces for the past which were } \\
\text { associated with reduced DMN RSFC (integrity) }\end{array}$ \\
\hline \multicolumn{3}{|c|}{ Zurich, Switzerland; $n=25$; dose: $100 \mu g$ p.o.; randomized, double-blind; age: 26 (20-34) years; NCT0245 $1072^{\mathrm{a}}$, six had previous hallucinogen use } \\
\hline $\begin{array}{l}\text { Kraehenmann et al, 2017; } \\
\text { Preller et al, } 2017\end{array}$ & $5 \mathrm{D}-\operatorname{ASC}(n=22)$ & $\begin{array}{l}\text { Ketanserin blocked LSD-induced alterations in } \\
\text { consciousness }\end{array}$ \\
\hline Preller et al, 2017 & PANAS $(n=22)$ & $\begin{array}{l}\text { Greater positive than negative affect; ketanserin } \\
\text { blocked LSD-induced positive affect }\end{array}$ \\
\hline Preller et al, 2017 & Meaning of music $(n=22)$ & $\begin{array}{l}\text { Personally meaningless and neutral music more } \\
\text { meaningul }\end{array}$ \\
\hline Preller et al, 2017 & $\begin{array}{l}\text { BOLD signal to meaningless } \\
(n=22) \text { vs meaningful music }\end{array}$ & Increase in medial and lateral frontal brain areas \\
\hline \multicolumn{3}{|c|}{ 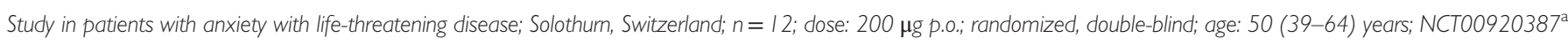 } \\
\hline Gasser et al, 2014 & $\begin{array}{l}\text { STAI, QLQ-30, SCL-90, HADS } \\
(n=11)\end{array}$ & $\begin{array}{l}\text { Significant reduction in STAl-state anxiety at } \\
2 \text { months compared with baseline and beneficial } \\
\text { trend-effects on other outcomes }\end{array}$ \\
\hline Liechti et al, 2017 & $\operatorname{MEQ}(n=11)$ & Induction of mystical-type experiences \\
\hline Gasser et al, 2015 & STAl, interviews $(n=9)$ & $\begin{array}{l}\text { Significant reduction in STAI-state and trait anxiety } \\
\text { at } 12 \text { months compared with baseline, rise in } \\
\text { reported quality of life }\end{array}$ \\
\hline
\end{tabular}

Abbreviations: AMRS, Adjective Mood Rating Scale; ARCl, Addiction Research Center Inventory; ASL, arterial spin labeling; AUC, area under the concentration-time curve; $C_{\max }$, maximal plasma concentration; CIS, creative imagination scale; 5D-ASC, 5 dimensions of altered states of consciousness scale; DMN, default mode network; FERT, face emotion recognition task; GEMS, Geneva emotional music scale; HADS, hospital anxiety and depression scale; MEG, magnetoencephalography; MEQ, mystical experience questionnaire; MET, multifaceted empathy test; MIT, mental imagery test; $n$, number of subjects in the entire study or for whom the respective outcome was reported; NR, not reported or not registered; PANAS, positive and negative affect scale; PSI, psychotic states inventory; QLQ-30, quality of life questionnaire 30-item version; RSFC, resting-state functional connectivity; rsfMRI, resting-state functional magnetic brain imaging; SCL-90, symptom check list-90; STAI, state-trait anxiety inventory; $\mathrm{SVO}$, social value orientation test; $T_{\max }$, time to $\mathrm{C}_{\max } t_{1 / 2}$, plasma half-life; VAS, visual analog scale.

${ }^{a}$ ClinicalTrials.gov trial registry number.

effects of LSD on functional magnetic resonance imaging (fMRI) study outcomes across subjects with prior LSD use (Speth et al, 2016; Tagliazucchi et al, 2016).

Music has typically been used in substance-assisted psychotherapy (Gasser et al, 2014, 2015; Johnson et al, 2008). Several modern studies assessed the interactive effects of LSD and listening to music. LSD enhanced the emotional response to music and produced greater feelings of wonder and transcendence compared with listening to music after placebo (Kaelen et al, 2015). LSD increased eyes-closed imagery or seeing scenes from the past, but listening to music did not interact with these subjective effects of LSD on imagery (Kaelen et al, 2016). Other researchers found that
LSD significantly increased ratings of music excerpts that were previously rated as personally meaningless or neutral (Preller et al, 2017). Thus, LSD attributed meaning to previously meaningless stimuli (Preller et al, 2017).

\section{Autonomic and Adverse Effects}

LSD moderately increased blood pressure, heart rate, body temperature, and pupil size (Dolder et al, 2016; Kaelen et al, 2015; Schmid et al, 2015). The sympathomimetic effects of 100 and $200 \mu \mathrm{g}$ doses of LSD were similar (Dolder et al, 2016, 2017) and less pronounced than those of MDMA and stimulants (Hysek et al, 2014b). Acute adverse effects up to 
10-24 h after LSD administration included difficulty concentrating, headache, dizziness, lack of appetite, dry mouth, nausea, imbalance, and feeling exhausted. Headaches and exhaustion may last up to $72 \mathrm{~h}$ (Dolder et al, 2016; Schmid et $a l, 2015)$. No severe adverse reactions were reported in modern LSD studies (Carhart-Harris et al, 2016b; Dolder et al, 2016; Kaelen et al, 2015; Preller et al, 2017; Schmid et al, 2015). This is consistent with the view that LSD is relatively safe when used in medical settings and according to safety guidelines (Johnson et al, 2008). LSD is physically non-toxic, but there are psychological risks especially when it is used in unsupervised settings. In addition, it is important to note that many novel hallucinogens are being used and may even be sold as LSD but have a different pharmacology and possibly risk profile than LSD (Rickli et al, 2015, 2016). LSD has typically been reported to produce flashbacks. Flashbacks after LSD can be defined as episodic and short (seconds or minutes) replications of elements of previous substancerelated experiences (Holland and Passie, 2011). In a webbased survey among hallucinogen users, greater past LSD use was a predictor of the probability of experiencing unusual substance-free visual experiences (Baggott et al, 2011). Clinically significant flashbacks are also defined as hallucinogen persisting perception disorder (HPPD). This disorder is considered rare and occurs almost exclusively in the context of illicit recreational use or/and in patients with anxiety disorders and it typically will have a limited course of months to a year (Halpern and Pope, 1999; Holland and Passie, 2011; Johnson et al, 2008). In controlled nontherapeutic research settings, psilocybin did not produce HPPD or flashbacks (Studerus et al, 2011). However, the prevalence and relevance of HPPD is unclear and needs to be studied (Halpern et al, 2016).

\section{Endocrine Effects}

LSD acutely increased plasma concentrations of cortisol (Strajhar et al, 2016), prolactin, oxytocin, and epinephrine (Schmid et al, 2015). LSD does not increase plasma concentrations of norepinephrine (Schmid et al, 2015), testosterone, or progesterone (Strajhar et al, 2016). The endocrine effects of LSD are consistent with those of other serotonergic substances including psilocybin, DMT, and MDMA (Hasler et al, 2004; Hysek et al, 2014b; Seibert et al, 2014; Strassman and Qualls, 1994a).

\section{Model Psychosis}

LSD $(75 \mu$, i.v.) increased subjective ratings of cognitive disorganization and delusional thinking (Carhart-Harris et $a l, 2016 \mathrm{~b})$. Disordered cognition has been suggested to be a more fundamental characteristic of LSD's effects than positive or negative mood (Carhart-Harris et al, 2016b). Nevertheless, the LSD experience was not dominated by unpleasant psychosis-like phenomena but rather characterized by an overall positive mood state in the majority of subjects (Carhart-Harris et al, 2016b). Investigators rated subjects as more distant from reality and happy after administration of $200 \mu \mathrm{g}$ LSD, whereas ratings of anxiety and paranoid thinking did not increase (Schmid et al, 2015). Patients with schizophrenia present deficits in sensorimotor gating, reflected by prepulse inhibition (PPI) of the startle response. LSD acutely disrupts PPI in both animals (Halberstadt and Geyer, 2010) and healthy human subjects (Schmid et al, 2015), producing deficits in information processing that are similar to those observed in schizophrenia. Similarly, inhibitory processes are impaired in schizophrenia and in healthy subjects after administration of LSD (Schmidt et al, 2017).

\section{Emotional Processing}

LSD impaired the recognition of sad and fearful faces (Dolder et al, 2016) and enhanced emotional empathy (Dolder et al, 2016), similar to psilocybin (Kometer et al, 2012; Preller et al, 2015) and MDMA (Hysek et al, 2014a; Kuypers et al, 2017). These effects of LSD on emotion processing may be considered useful in LSD-assisted psychotherapy. However, LSD also impaired the identification of complex emotions (Dolder et al, 2016).

\section{Functional Brain Imaging}

LSD acutely decreased the functional integrity of brain networks (Figure 2a) and the separation between networks (Carhart-Harris et al, 2016c; Tagliazucchi et al, 2016) (Figure 2b). At the whole-brain level, LSD increased functional connectivity between various brain regions (Figure 3). LSD also increased measures of functional 'brain entropy' (ie, the predictability of resting-state fMRI time series) across many functional systems (Lebedev et al, 2016). The acute LSD-induced global increase in 'brain entropy' was associated with trait openness that was assessed 14 days later (Lebedev et al, 2016). LSD increased thalamocortical restingstate functional connectivity (RSFC) (Mueller et al, 2017b; Tagliazucchi et al, 2016), overall connectivity in high-level cortical regions and the thalamus, and connectivity between normally more dissociated resting-state networks (Tagliazucchi et al, 2016). These findings indicate more globally synchronized activity within the brain and a reduction of network separation while under the pharmacological effects of LSD. Similar decreases in within-network integrity (Carhart-Harris et al, 2014; Muthukumaraswamy et al, 2013) and increases in between-network connectivity (Carhart-Harris et al, 2013; Roseman et al, 2014) have been observed under psilocybin. The LSD-induced increases in global connectivity, particularly in the temporo-parietal junction and insular cortex, correlated with feelings of moderate 'ego dissolution' that were produced by LSD (Tagliazucchi et al, 2016). 'Ego dissolution' refers to a disintegration of the sense of possessing a 'self or identity that is distinct from others and from the environment (Preller and Vollenweider, 2016; Tagliazucchi et al, 2016). In addition, LSD-induced RSFC between the thalamus and right fusiform gyrus and insula correlated with subjective visual and auditory alterations, respectively (Mueller et al, 2017b). Remaining to be determined is the way in which LSDinduced increases in thalamocortical connectivity may be linked to the thalamic gating of perceptions (Mueller et al, $2017 b$ ). In contrast to the higher connectivity between neural networks while under the effects of LSD, LSD globally decreased within-network RSFC (integrity) and withinnetwork signal variance (Carhart-Harris et al, 2016c) (Figure 2a). Specifically, LSD decreased default mode 


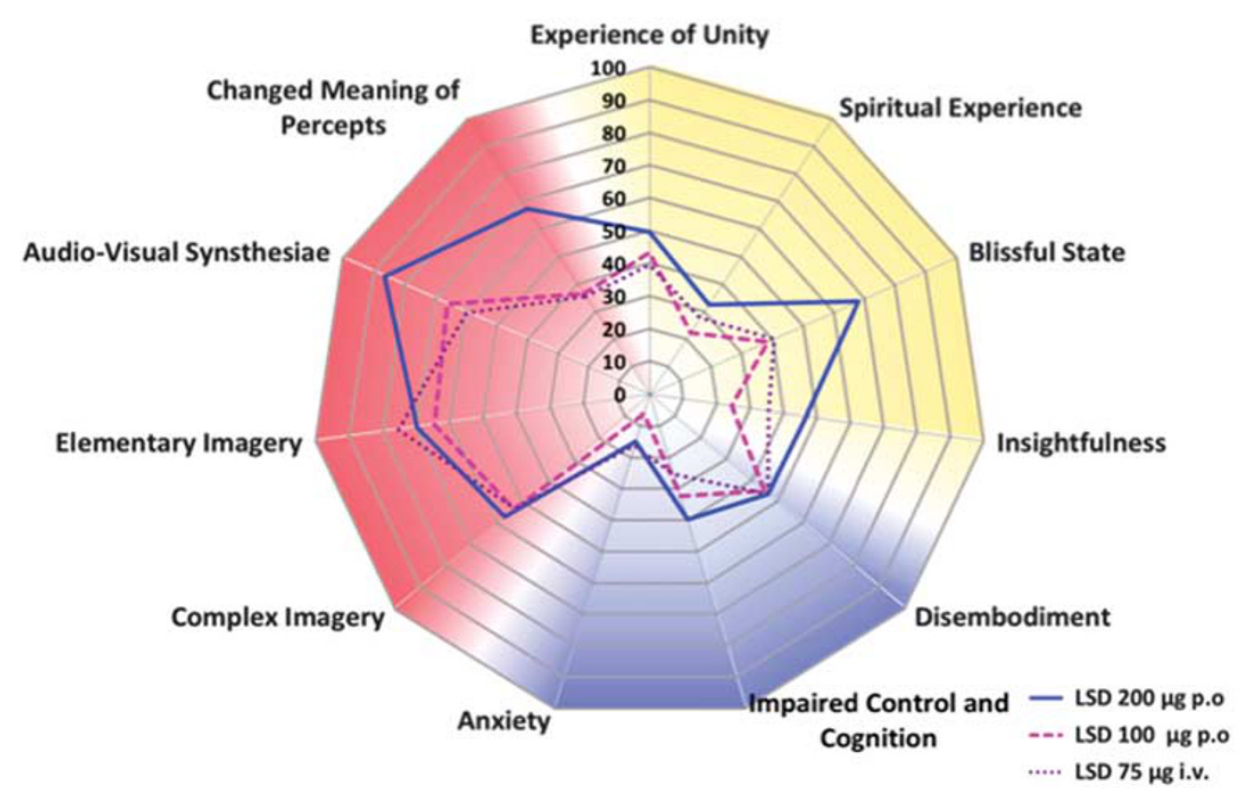

Anxious ego-dissolution

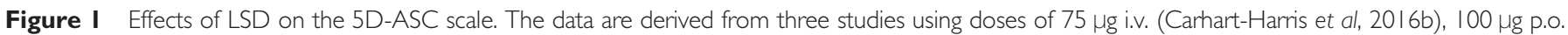
(Liechti et al, 20 I7), and $200 \mu \mathrm{g}$ p.o. (Schmid et al, 20I5) LSD in healthy subjects. LSD predominantly increased ratings in subscales of the dimensions oceanic boundlessness and visionary restructuralization. LSD-induced increases in subscales of the anxious ego-dissolution dimension and in particular in the anxiety scale were relatively small. LSD-induced changes on the 5D-ASC scale were significant compared with placebo for all LSD doses and all of the scales, with the exception of the effects of the $200 \mathrm{\mu g}$ dose on anxiety. There were no statistical differences in the effects of the intravenous $75 \mathrm{\mu g}$ (Carhart-Harris et al, $2016 \mathrm{~b}$ ) and oral $100 \mathrm{\mu g}$ (Liechti et al, 2017) dose of LSD on 5D-ASC scale ratings (data provided by the authors). At $200 \mu \mathrm{g}$, LSD produced significant and relevantly higher ratings of blissful state, insightfulness, and changed meaning of percepts compared with $100 \mu g$. The data are expressed as the mean in 24 , I6, and 20 subjects for the $100 \mu g, 200 \mu g$, and $75 \mu \mathrm{g}$ doses of LSD, respectively.

network (DMN) integrity (Carhart-Harris et al, 2016c) as previously shown for psilocybin (Carhart-Harris et al, 2014), and this LSD-induced disintegration of the DMN correlated with ratings of ego dissolution (Carhart-Harris et al, 2016c; Tagliazucchi et al, 2016). Furthermore, reductions of RSFC in the DMN (ie, DMN disintegration) were associated with fewer mental spaces for the past (ie, decreased mental time travel to the past) while under the effects of LSD (Speth et al, 2016). Increases in DMN RSFC have been described in depression, and decreases in DMN RSFC that are induced by LSD may be linked to its potential antidepressant effects (Carhart-Harris et al, 2016a).

Arterial spin labeling analyses revealed greater cerebral blood flow in the visual cortex that was induced by LSD, and this increase was associated with ratings of complex imagery on the 5D-ASC (Carhart-Harris et al, 2016c). LSD also strongly increased RSFC between the primary visual cortex (V1) and cortical and subcortical brain regions, and this effect correlated with 5D-ASC ratings of elementary or complex hallucinations (Carhart-Harris et al, 2016c). Greatly expanded V1 functional connectivity that is induced by LSD may indicate that a greater proportion of the brain processes visual information than under normal conditions (CarhartHarris et al, 2016c). Further analyses found that LSD administration altered eyes-closed spontaneous activity within retinotopically organized patches of the V1 and neighboring visual regions (V3), similar to visual stimulation (Roseman et al, 2016). Thus, the primary visual system is altered by LSD and behaves as if it perceives spatially localized visual information when in fact there is none (Roseman et al, 2016), which is consistent with the notion of 'seeing with the eyes shut' (Carhart-Harris et al, 2016c; Roseman et al, 2016).

LSD-induced decreases in RSFC between the parahippocampus and the rest of the brain (particularly the retrosplenial and posterior cingulate cortex) correlated with VAS ratings of ego dissolution and altered meaning on the 5DASC (Carhart-Harris et al, 2016c). Similarly, psilocybin altered activity in parahippocampal-retrosplenial cortex circuit measured with EEG and this effect correlated with spirituality and insigthfulness ratings on the 5D-ASC (Kometer et al, 2015). LSD increased blood oxygen-leveldependent activity of the supplementary motor area and prefrontal cortex in response to music without personal meaning or relevance compared with personally meaningful and neutral music, indicating enhanced activity in brain areas that are involved in self-referential cognition and processing (Preller et al, 2017). LSD reduced left amygdala reactivity to the presentation of fearful faces (Mueller et al, 2017a). Psilocybin similarly decreased amygdala reactivity to negative facial expressions (Kraehenmann et al, 2015). Lower fear perception (Dolder et al, 2016) and amygdala reactivity may be useful during psychotherapy. Magnetoencephalography showed that LSD decreased oscillatory power throughout the brain during eyes-closed rest (Carhart-Harris et al, 2016c) as similarly shown for psilocybin (Kometer et al, 
a
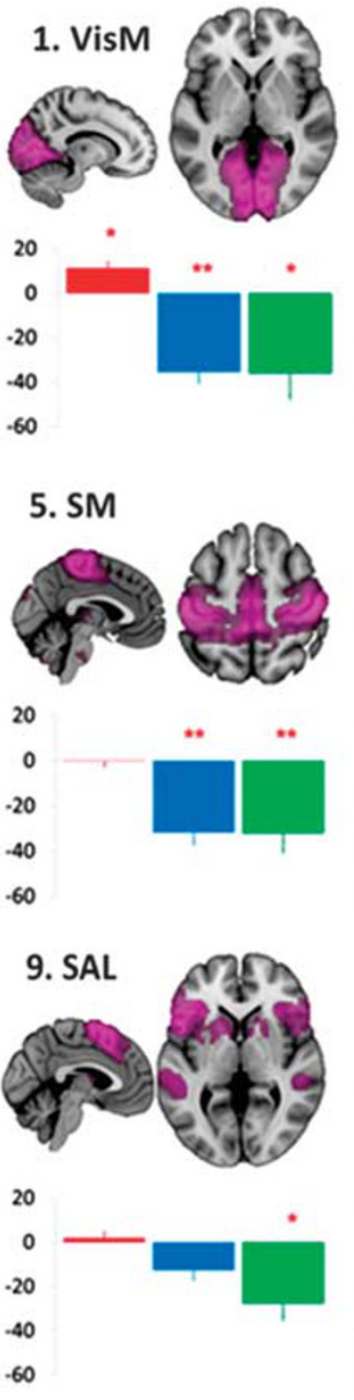

b

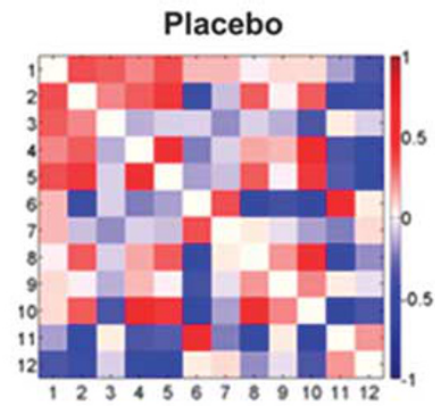

.60

20

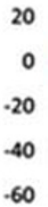

RSN: CBF, integrity, signal variance
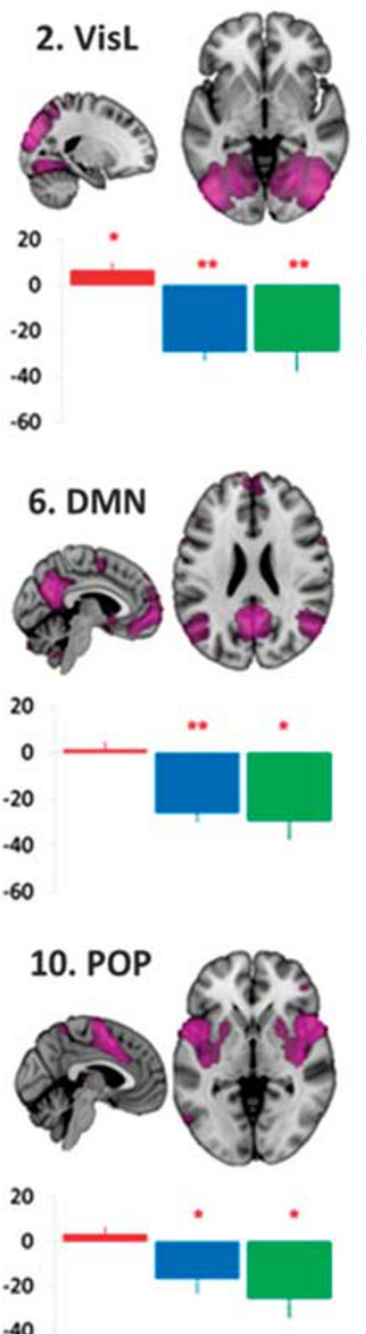

RSN segregation

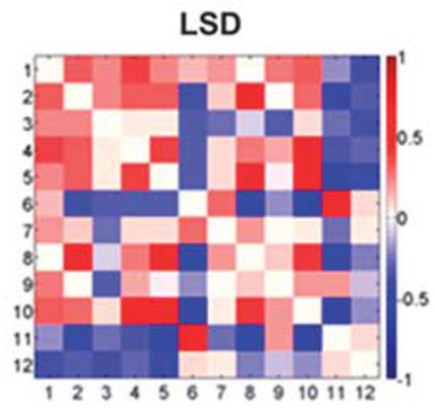

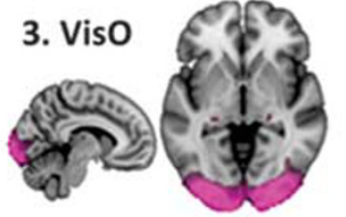

20

0

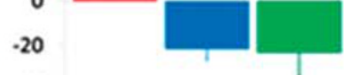

$-40$

$-60$
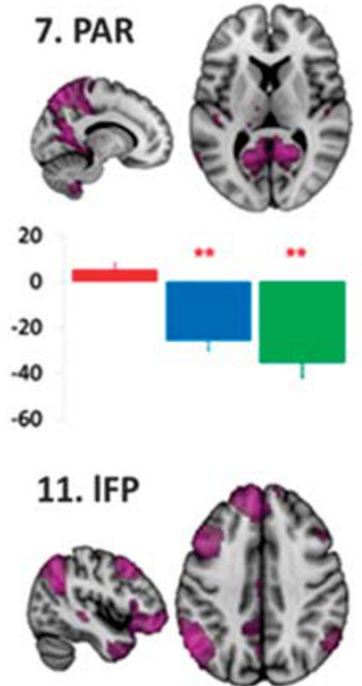

20
0
-20
-40
-60

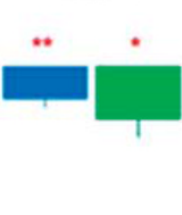

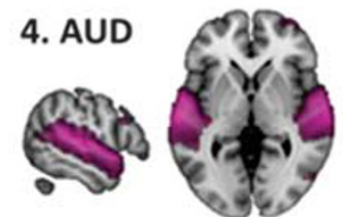

20

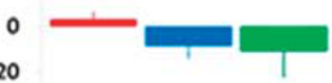

$-40$

.60
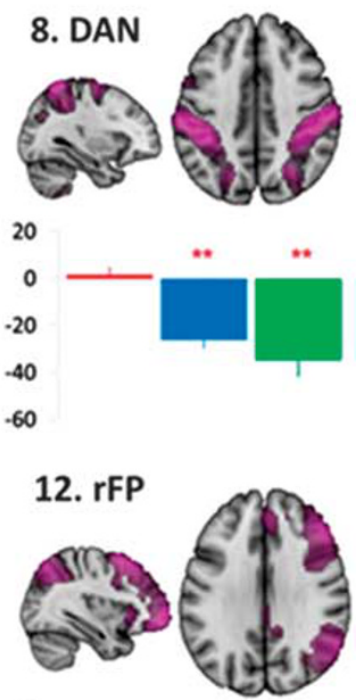

20
0
-20
-40
.60

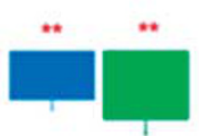

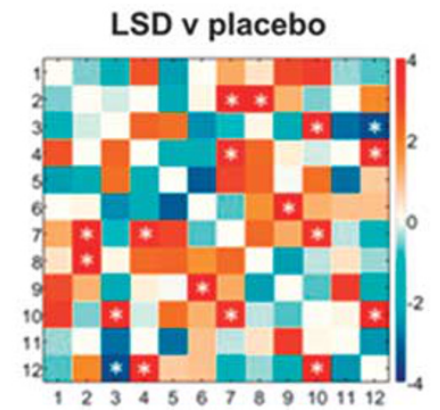

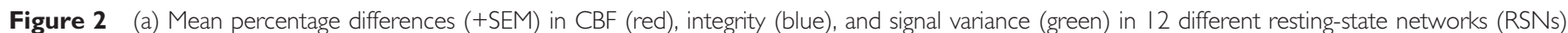

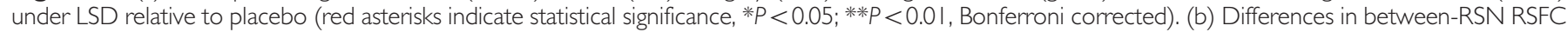

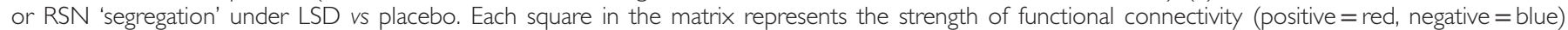

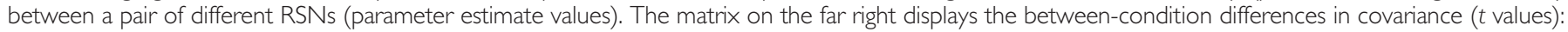

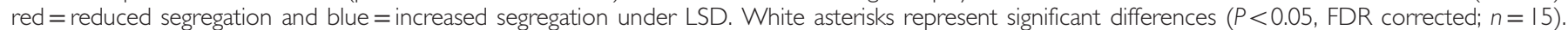
Reproduced from Carhart-Harris et al (2016c).

2015; Muthukumaraswamy et al, 2013) and ayahuasca (Riba et al, 2002). After LSD administration, lower alpha power correlated with subjective ratings of simple hallucinations (Carhart-Harris et al, 2016c). Lower alpha power in occipital sensors correlated with increases in primary visual cortex RSFC (Carhart-Harris et al, 2016c). Modern positron emission tomography (PET) and single-photon emission computed tomography studies of LSD have not yet been 


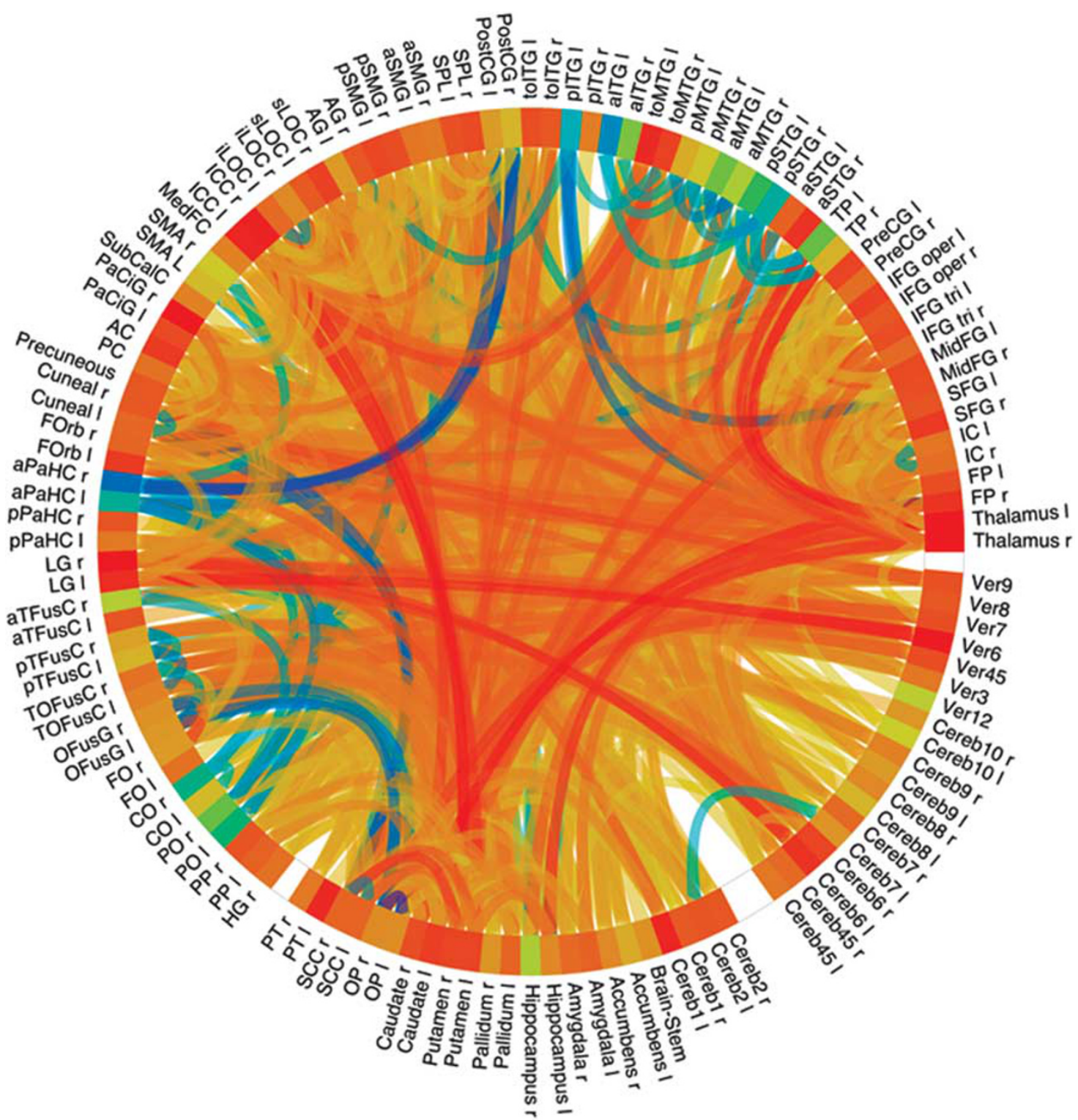

Figure 3 Connectome ring showing functional connectivity between 132 regions covering the whole brain. Contrast LSD vs placebo, $P<0.05$, FDR. Yellow-red indicates increased functional connectivity, blue indicates decreased connectivity. Figure provided by F Mueller from the Basel fMRI study (Mueller et al, 20I7b).

conducted. Other 5-HT hallucinogens, such as psilocybin, ayahuasca, and mescaline, increased metabolic indices in frontal brain areas Hallucinogen-induced hyperfrontality is hypothesized to reflect increased frontal activity due to flooding with information (Geyer and Vollenweider, 2008; Vollenweider et al, 1997). In contrast, in an fMRI study, psilocybin decreased blood flow and BOLD signal in the thalamus, anterior cingulate, medial prefrontal, and cingulate cortices (Carhart-Harris et al, 2012). It is not yet clear what the different imaging modalities represent and how these inconsistencies can be explained. It has been proposed that the PET study findings of hyperfrontality reflect the increased neuronal firing activity while fMRI BOLD measures correlate with cortical oscillatory activity (Halberstadt, 2015). Altogether, the first modern imaging studies of LSD have provided preliminary information on the neural correlates of altered states of mind that are induced by LSD. However, there are many limitations. Much data have been derived from only a few small studies. Chance findings should be expected especially with regard to the RSFC data. LSD may also have direct actions on vascular resistance and blood flow that may confound neuroimaging data. These preliminary findings need to be confirmed in larger studies and by different research groups.

\section{Clinical Pharmacology}

The pharmacokinetics of LSD have been well investigated only for oral doses of 100 and $200 \mu$ g (Dolder et al, 2015b, 2017; Steuer et al, 2016). LSD concentration-time and subjective effect-time curves are shown in Figure 4. No data are available on the concentration-time course of the 
intravenous dose of $75 \mu \mathrm{g}$ LSD that was used in the London studies. The pharmacokinetics of LSD are dose-proportional, and elimination kinetics are linear up to $12 \mathrm{~h}$ (Dolder et al, 2015b, 2017; Steuer et al, 2016). Maximal plasma concentrations are reached $1.5 \mathrm{~h}$ after oral administration (Dolder et al, 2015b, 2017) (Figure 4). The elimination half-life is $\sim 3 \mathrm{~h}$ (Dolder et al, 2015b, 2017). LSD can be detected in blood plasma up to $12-24 \mathrm{~h}$ after administration, depending on the dose (Dolder et al, 2017). 2-Oxo-3-hydroxy-LSD (Oxo-HOLSD) is the major metabolite of LSD and is detectable in urine for a longer time than LSD (Dolder et al, 2015a, b; Steuer et al, 2016). Oxo-HO-LSD and minor metabolites of LSD can only be detected at very low concentrations in blood plasma and serum $(<0.3 \mathrm{ng} / \mathrm{ml}$ ) (Dolder et al, 2015a, b; Steuer et al, 2016) but are present at higher concentrations in urine (Dolder et al, 2015a). The intravenous dose of $75 \mu \mathrm{g}$ LSD that was used in the London studies likely corresponds to the oral dose of $100 \mu \mathrm{g}$ that was used in the Basel and Zurich studies, based on the comparable effects on the 5D-ASC (Carhart-Harris et al, 2016b; Liechti et al, 2017) (Figure 1). The subjective, cognitive, and sympathomimetic effects of oral LSD closely reflected the time course of LSD concentrations in plasma (Dolder et al, 2015b, 2017) (Figure 4). Subjective effects of LSD peaked $2.5 \mathrm{~h}$ after administration and lasted for $8 \mathrm{~h}$ and $12 \mathrm{~h}$ after administration of $100 \mu \mathrm{g}$ and $200 \mu \mathrm{g}$, respectively (Dolder et al, 2017) (Figure 4). After intravenous administration of $75 \mu \mathrm{g} \mathrm{LSD}$, subjective effects peaked at $45-120 \mathrm{~min}$ and lasted $7-8 \mathrm{~h}$ (Carhart-Harris et al, 2016b, c; Kaelen et al, 2015). After a single dose of LSD, the pharmacodynamic effects lasted as long as LSD was present in the body, with no evidence of acute tolerance to the effects of LSD (Dolder et al, 2017). Tolerance has been reported with repeated daily LSD administration over 3-7 days (Belleville et al, 1956).

\section{Mid- and Long-Term Effects}

In comparison to other illicit substances, epidemiological studies indicate that the use of classic hallucinogens is associated with lower psychological distress, lower suicidality, and lower mental health problems (Hendricks et al, 2015). Long-lasting positive effects were documented in modern studies after controlled administration of psilocybin (Griffiths et al, 2011; MacLean et al, 2011) and ayahuasca (Bouso et al, 2012) but have not yet been reported in modern experimental laboratory studies of LSD. Controlled administration of LSD in healthy subjects increased optimism and trait openness 2 weeks after administration and produced trends toward decreases in distress and delusional thinking (Carhart-Harris et al, 2016b). In addition, the greatest increases in openness were observed in subjects who presented both the highest acute LSD-induced enhancements of ego dissolution during music listening and greater brain entropy in frontal areas (Lebedev et al, 2016). However, the reported increases in optimism and personality trait openness 14 days after LSD administration were observed in subjects with on average already 14 previous uses of LSD (Carhart-Harris et al, 2016b; Lebedev et al, 2016) raising the question of how open and optimistic participants can actually become or whether these effects are rather transient.

\section{STUDIES IN PATIENTS}

Early studies from the 1950s to 1970s indicated that LSD may have antidepressive and anxiolytic properties (Dos Santos et al, 2016; Passie et al, 2008; Rucker et al, 2016). LSDassisted psychotherapy was often performed in patients with anxiety and cancer (Pahnke et al, 1969; Sheehan, 1972) and in patients with depression or related disorders (Rucker et al, 2016). These early practices and studies were relatively poorly documented methodologically, and replication in modern studies is needed. Single or few doses of LSD also reportedly lessened cluster headache and induced remission more effectively than conventional medications (Schindler et al, 2015). However, no controlled studies have been conducted. LSD was also well studied as treatment for alcohol use disorder (Krebs and Johansen, 2012). LSD and other hallucinogens are misused but are not addictive substances leading to compulsive drug taking, withdrawal or self-administration in animals (Fantegrossi et al, 2008; Nichols, 2004). Recent trials investigated psilocybin in patients with alcohol and nicotine use disorder
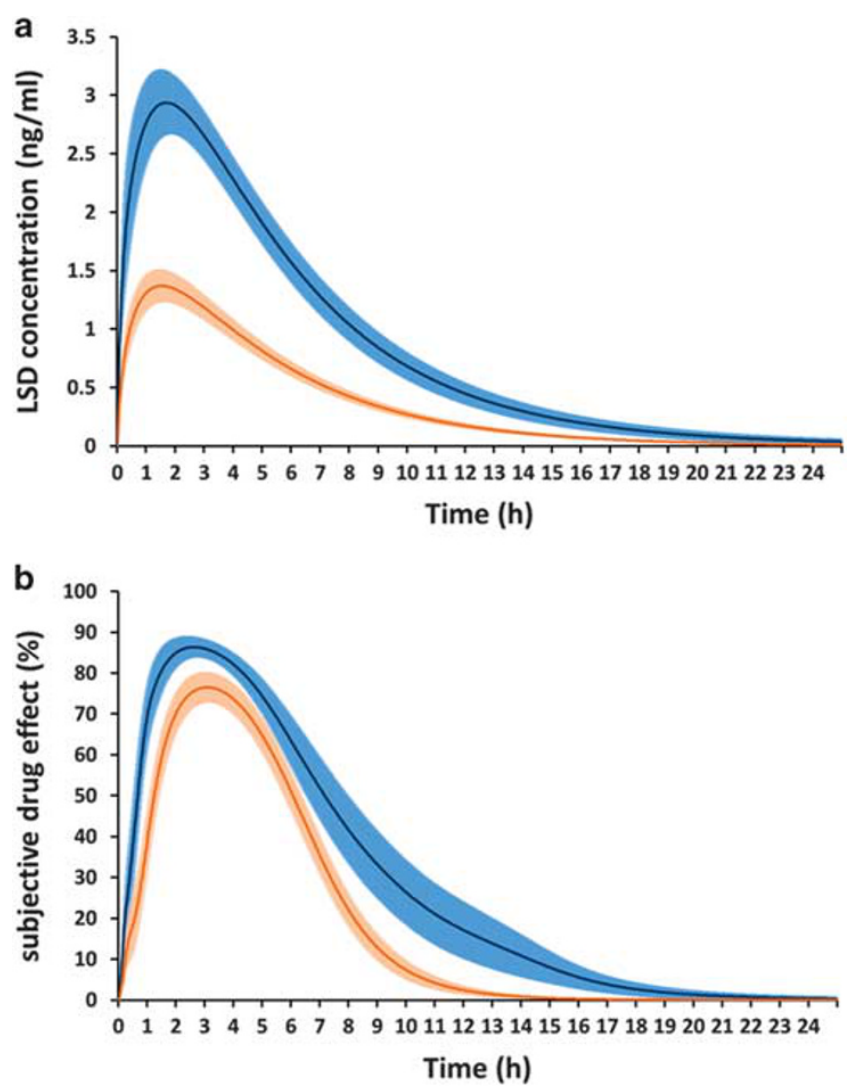

Figure 4 Pharmacokinetics and pharmacodynamics of LSD. LSD concentration-time (a) and subjective effect-time (b) curves. LSD was administered at a dose of 100 and $200 \mu g$ p.o. to 24 and 16 healthy subjects, respectively, at the time point $t=0$. Subjective LSD effects ('any subjective drug effects') were assessed repeatedly using VASs (0-100\%) along with blood samples to determine plasma concentrations of LSD (Dolder et al, 2015b; Dolder et al, 2016; Dolder et al, 2017). The LSD concentration curves (a) represent the mean \pm SEM of the individual curves fitted to the observed data using a I-compartment model. The subjective drug effect curves (b) represent the mean \pm SEM of the individual curves fitted to the observed data using a sigmoidal $\mathrm{E}_{\max }$ model linked to the predicted concentrations (Dolder et al, 2017). 
(Bogenschutz et al, 2015; Johnson et al, 2014), major depression, and anxiety (Carhart-Harris et al, 2016a; Griffiths et al, 2016; Grob et al, 2011; Ross et al, 2016). However, in the past 40 years, no studies of LSD have been conducted in humans until very recently, and only one modern trial evaluated LSD in patients (Gasser et al, 2014, 2015) (Table 2). The trial assessed the effects of LSD-assisted psychotherapy on anxiety in 11 patients with life-threatening diseases (eight with cancer). Eight patients received $200 \mu \mathrm{g}$ LSD twice, and three patients received active placebo (a low dose of $20 \mu \mathrm{g}$ LSD) twice in two sessions 2-3 weeks apart, with an open-label crossover to $200 \mu \mathrm{g}$ LSD after the first randomized double-blind treatment phase. At study entry, all of the patients presented higher ratings of anxiety on the state-trait anxiety inventory (STAI), six were diagnosed with generalized anxiety disorder, and seven were diagnosed with major depression. The study found a significant decrease in STAI anxiety 2 months after the two LSD sessions compared with baseline anxiety scores. STAI scores did not decrease in the placebo group. However, the placebo control group was too small for statistical comparisons with the treatment group and therefore a valid control was missing. The study also found non-significant decreases in depression and increases in quality of life (Gasser et al, 2014). A follow-up study at 12 months in nine patients reported sustained decreases in anxiety, an increase in quality of life, and no lasting adverse reactions after LSD, but the follow-up lacked a control group (Gasser et al, 2015). No drug-related severe adverse effects were reported, with no panic reactions or other medical or psychiatric complications. Prolonged psychotic reactions were reportedly rare in patients who received LSD during psychotherapy (Passie et al, 2008). Because the therapist used effective existential and meaningbased psychotherapeutic methods in both the treatment and control groups, the possible added benefits of LSD are not yet known. In addition, different and mostly non-evidence-based therapies have been used in psychedelic-assisted therapy trials making comparisons between studies difficult. A larger trial that uses LSD in patients who suffer from anxiety associated with severe somatic disease and anxiety disorder is conducted in Switzerland (NCT03153579). In addition, two high-quality studies recently reported the efficacy of psilocybin in the treatment of anxiety and depression associated with lifethreatening cancer (Griffiths et al, 2016; Ross et al, 2016).

\section{FUTURE DIRECTIONS}

New areas of research on hallucinogens, including LSD, have just recently opened, and many questions remain unanswered. With regard to potential therapeutic long-term effects of single-dose hallucinogen administration, unclear is whether these effects depend on a direct pharmacological action or on the acute psychological response. Differential indications might be associated with different aspects of mechanisms of action. Novel dose-response studies of the acute effects of LSD are lacking, and direct comparisons with psilocybin need to be made. Neuroimaging studies may help determine whether long-term changes in mood can be linked to changes in brain activity and how such patterns change before, during, and after the acute effects of LSD and other hallucinogens. The dissociable effects of the substance itself and psychotherapy on outcomes also need to be elucidated, in addition to their interactive effects. Larger studies need to validly define the benefits of using hallucinogens as an adjunct to psychotherapy and the patient characteristics that may predict such additional benefits of hallucinogens. Unclear are the aspects of the acute response to hallucinogens that best predict good long-term therapeutic outcomes. Acute mystical-type effects of psilocybin have been associated with greater reductions of anxiety and depression in patients (Garcia-Romeu et al, 2015; Griffiths et al, 2016; Ross et al, 2016). This association, however, may not imply causation. Other aspects of the acute peak response to hallucinogens could be equally important (Dolder et al, 2016; Liechti et al, 2017). Many practical aspects of clinical trials that evaluate the effects of LSD also need to be resolved. Clinical studies have generally become extremely costly because of overregulation. This is especially problematic for LSD research because industry funding is unlikely. In many countries, the scheduling of LSD still impedes or prohibits clinical research.

The mechanism of the therapeutic actions of LSD is unclear. The acute psychedelic or mystical peak experience characterized by a loss of usual sense of self, sense of unity, transcendence of time and space, and feelings of positive mood, awe, and meaning (Pahnke et al, 1970) may restructure patients' emotional trust, situational understanding, habits, and views (Gasser et al, 2015). Lower RSFC in the DMN may be linked to lower rumination and depression (Carhart-Harris et al, 2016c). Enhanced neurogenesis may be associated with antidepressant effects. Acutely reduced fear recognition and amygdala reactivity may facilitate the processing of negative information (Dolder et al, 2016; Mueller et al, 2017a), and feelings of closeness and trust enhance the patient-therapist relationship (Dolder et al, 2016; Schmid et al, 2015). Irrespective of the mechanism, if LSD in only a few doses may indeed improve health, this novel treatment paradigm needs to be studied further in modern clinical studies.

\section{CONCLUSIONS}

A few single administrations of LSD or related substances within a therapeutic setting may be beneficial for patients with anxiety associated with severe illness, depression, or addiction. These old-new treatments may have a potential in psychiatry. As professionals, we should actively study these new options so patients who are in need will not look elsewhere for unproven treatments from unregulated sources. More methodologically sound research on the psychological and biological mechanisms and therapeutic potential of LSD in psychiatry is needed.

\section{FUNDING AND DISCLOSURE}

The authors declare no conflict of interest.

\section{ACKNOWLEDGMENTS}

The author acknowledges $\mathrm{P}$ Dolder and F Mueller for comments on the manuscript, F Muller and P Vizeli for assistance with figure design, and $M$ Arends for text editing. 
This work was funded by the Swiss National Science Foundation (Grant no. 320030_170249).

\section{REFERENCES}

Baggott MJ, Coyle JR, Erowid E, Erowid F, Robertson LC (2011). Abnormal visual experiences in individuals with histories of hallucinogen use: a Web-based questionnaire. Drug Alcohol Depend 114: 61-67.

Belleville RE, Fraser HF, Isbell H, Wikler A, Logan CR (1956). Studies on lysergic acid diethylamide (LSD-25): I. Effects in former morphine addicts and development of tolerance during chronic intoxication. AMA Arch Neurol Psychiatry 76: 468-478.

Bogenschutz MP, Forcehimes AA, Pommy JA, Wilcox CE, Barbosa PC, Strassman RJ (2015). Psilocybin-assisted treatment for alcohol dependence: a proof-of-concept study. J Psychopharmacol 29: 289-299.

Bouso JC, Gonzalez D, Fondevila S, Cutchet M, Fernandez X, Ribeiro Barbosa PC et al (2012). Personality, psychopathology, life attitudes and neuropsychological performance among ritual users of Ayahuasca: a longitudinal study. PLoS ONE 7: e42421.

Carhart-Harris RL, Bolstridge M, Rucker J, Day CM, Erritzoe D, Kaelen $\mathrm{M}$ et al (2016a). Psilocybin with psychological support for treatment-resistant depression: an open-label feasibility study. Lancet Psychiatry 3: 619-627.

Carhart-Harris RL, Erritzoe D, Williams T, Stone JM, Reed LJ, Colasanti A et al (2012). Neural correlates of the psychedelic state as determined by fMRI studies with psilocybin. Proc Natl Acad Sci USA 109: 2138-2143.

Carhart-Harris RL, Kaelen M, Bolstridge M, Williams TM, Williams LT, Underwood R et al (2016b). The paradoxical psychological effects of lysergic acid diethylamide (LSD). Psychol Med 46: 1379-1390.

Carhart-Harris RL, Kaelen M, Whalley MG, Bolstridge M, Feilding A, Nutt DJ (2015). LSD enhances suggestibility in healthy volunteers. Psychopharmacology 232: 785-794.

Carhart-Harris RL, Leech R, Erritzoe D, Williams TM, Stone JM, Evans J et al (2013). Functional connectivity measures after psilocybin inform a novel hypothesis of early psychosis. Schizophr Bull 39: 1343-1351.

Carhart-Harris RL, Leech R, Hellyer PJ, Shanahan M, Feilding A, Tagliazucchi E et al (2014). The entropic brain: a theory of conscious states informed by neuroimaging research with psychedelic drugs. Front Hum Neurosci 8: 20.

Carhart-Harris RL, Muthukumaraswamy S, Roseman L, Kaelen M, Droog W, Murphy K et al (2016c). Neural correlates of the LSD experience revealed by multimodal neuroimaging. Proc Natl Acad Sci USA 113: 4853-4858.

Dolder PC, Liechti ME, Rentsch KM (2015a). Development and validation of a rapid turboflow LC-MS/MS method for the quantification of LSD and 2-oxo-3-hydroxy LSD in serum and urine samples of emergency toxicological cases. Anal Bioanal Chem 407: 1577-1584.

Dolder PC, Schmid Y, Haschke M, Rentsch KM, Liechti ME (2015b). Pharmacokinetics and concentration-effect relationship of oral LSD in humans. Int J Neuropsychopharmacol 19: pyv072.

Dolder PC, Schmid Y, Mueller F, Borgwardt S, Liechti ME (2016). LSD acutely impairs fear recognition and enhances emotional empathy and sociality. Neuropsychopharmacology 41: 2638-2646.

Dolder PC, Schmid Y, Steuer AE, Kraemer T, Rentsch KM, Hammann F et al (2017). Pharmacokinetics and pharmacodynamics of lysergic acid diethylamide in healthy subjects. Clin Pharmacokinetics (e-pub ahead of print; doi:10.1007/s40262017-0513-9).

Dos Santos RG, Osorio FL, Crippa JA, Riba J, Zuardi AW, Hallak JE (2016). Antidepressive, anxiolytic, and antiaddictive effects of ayahuasca, psilocybin and lysergic acid diethylamide (LSD): a systematic review of clinical trials published in the last 25 years. Ther Adv Psychopharmacol 6: 193-213.

Fantegrossi WE, Murnane KS, Reissig CJ (2008). The behavioral pharmacology of hallucinogens. Biochem Pharmacol 75: 17-33.

Garcia-Romeu A, Griffiths RR, Johnson MW (2015). Psilocybinoccasioned mystical experiences in the treatment of tobacco addiction. Curr Drug Abuse Rev 7: 157-164.

Gasser P, Holstein D, Michel Y, Doblin R, Yazar-Klosinski B, Passie $\mathrm{T}$ et al (2014). Safety and efficacy of lysergic acid diethylamide-assisted psychotherapy for anxiety associated with life-threatening diseases. J Nerv Ment Dis 202: 513-520.

Gasser P, Kirchner K, Passie T (2015). LSD-assisted psychotherapy for anxiety associated with a life-threatening disease: a qualitative study of acute and sustained subjective effects. J Psychopharmacol 29: $57-68$

Geyer MA, Vollenweider FX (2008). Serotonin research: contributions to understanding psychoses. Trends Pharmacol Sci 29: $445-453$.

Gouzoulis-Mayfrank E, Heekeren K, Neukirch A, Stoll M, Stock C, Obradovic $M$ et al (2005). Psychological effects of (S)-ketamine and N,N-dimethyltryptamine (DMT): a double-blind, cross-over study in healthy volunteers. Pharmacopsychiatry 38: 301-311.

Griffiths RR, Johnson MW, Carducci MA, Umbricht A, Richards WA, Richards BD et al (2016). Psilocybin produces substantial and sustained decreases in depression and anxiety in patients with life-threatening cancer: a randomized doubleblind trial. J Psychopharmacol 30: 1181-1197.

Griffiths RR, Johnson MW, Richards WA, Richards BD, McCann U, Jesse R (2011). Psilocybin occasioned mystical-type experiences: immediate and persisting dose-related effects. Psychopharmacology 218: 649-665.

Grob CS, Danforth AL, Chopra GS, Hagerty M, McKay CR, Halberstadt AL et al (2011). Pilot study of psilocybin treatment for anxiety in patients with advanced-stage cancer. Arch Gen Psychiatry 68: 71-78.

Halberstadt AL (2015). Recent advances in the neuropsychopharmacology of serotonergic hallucinogens. Behav Brain Res 277: 99-120.

Halberstadt AL, Geyer MA (2010). LSD but not lisuride disrupts prepulse inhibition in rats by activating the $5-\mathrm{HT}_{2 \mathrm{~A}}$ receptor. Psychopharmacology 208: 179-189.

Halpern JH, Lerner AG, Passie T (2016). A review of hallucinogen persisting perception disorder (HPPD) and an exploratory study of subjects claiming symptoms of HPPD. Curr Top Behav Neurosci (e-pub ahead of print; doi: 10.1007/7854_2016_457).

Halpern JH, Pope HG Jr. (1999). Do hallucinogens cause residual neuropsychological toxicity? Drug Alcohol Depend 53: 247-256.

Hasler F, Grimberg U, Benz MA, Huber T, Vollenweider FX (2004). Acute psychological and physiological effects of psilocybin in healthy humans: a double-blind, placebo-controlled dose-effect study. Psychopharmacology 172: 145-156.

Hendricks PS, Thorne CB, Clark CB, Coombs DW, Johnson MW (2015). Classic psychedelic use is associated with reduced psychological distress and suicidality in the United States adult population. J Psychopharmacol 29: 280-288.

Holland D, Passie T (2011). Flaschback-Phänomene. Verlag für Wissenschaft und Bildung: Berlin, Germany.

Hollister LE, Hartman AM (1962). Mescaline, lysergic acid diethylamide and psilocybin comparison of clinical syndromes, effects on color perception and biochemical measures. Compr Psychiatry 3: 235-242.

Hysek CM, Schmid Y, Simmler LD, Domes G, Heinrichs M, Eisenegger C et al (2014a). MDMA enhances emotional empathy and prosocial behavior. Soc Cogn Affect Neurosci 9: 1645-1652.

Hysek CM, Simmler LD, Schillinger N, Meyer N, Schmid Y, Donzelli $\mathrm{M}$ et al (2014b). Pharmacokinetic and pharmacodynamic effects of methylphenidate and MDMA administered alone and in combination. Int J Neuropsychopharmacol 17: 371-381.

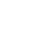


Johnson M, Richards W, Griffiths R (2008). Human hallucinogen research: guidelines for safety. $J$ Psychopharmacol 22: 603-620.

Johnson MW, Garcia-Romeu A, Cosimano MP, Griffiths RR (2014). Pilot study of the 5-HT2AR agonist psilocybin in the treatment of tobacco addiction. J Psychopharmacol 28: 983-992.

Kaelen M, Barrett FS, Roseman L, Lorenz R, Family N, Bolstridge M et al (2015). LSD enhances the emotional response to music. Psychopharmacology 232: 3607-3614.

Kaelen M, Roseman L, Kahan J, Santos-Ribeiro A, Orban C, Lorenz $\mathrm{R}$ et al (2016). LSD modulates music-induced imagery via changes in parahippocampal connectivity. Eur Neuropsychopharmacol 26: 1099-1109.

Kometer M, Pokorny T, Seifritz E, Volleinweider FX (2015). Psilocybin-induced spiritual experiences and insightfulness are associated with synchronization of neuronal oscillations. Psychopharmacology 232: 3663-3676.

Kometer M, Schmidt A, Bachmann R, Studerus E, Seifritz E, Vollenweider FX (2012). Psilocybin biases facial recognition, goal-directed behavior, and mood state toward positive relative to negative emotions through different serotonergic subreceptors. Biol Psychiatry 72: 898-906.

Kraehenmann R, Preller KH, Scheidegger M, Pokorny T, Bosch OG, Seifritz E et al (2015). Psilocybin-induced decrease in amygdala reactivity correlates with enhanced positive mood in healthy volunteers. Biol Psychiatry 78: 572-581.

Kraehenmann R, Pokorny D, Vollenweider L, Preller KH, Prokorny T, Seifritz E, Vollenwieder FX (2017). Dreamlike effects of LSD on waking imagery in humans depend on serotonin 2A receptor activation. Psychopharmacology (Berl) (in press); doi: 10.1007/ s00213-017-4610-0.

Krebs TS, Johansen PO (2012). Lysergic acid diethylamide (LSD) for alcoholism: meta-analysis of randomized controlled trials. J Psychopharmacol 26: 994-1002.

Krebs TS, Johansen PO (2013). Over 30 million psychedelic users in the United States. F1000 Res 2: 98.

Kuypers KPC, Dolder PC, Ramaekers JG, Liechti ME (2017). Multifaceted empathy of healthy volunteers after single doses of MDMA: a pooled sample of placebo-controlled studies. J Psychopharmacol 31: 589-598.

Lebedev AV, Kaelen M, Lovden M, Nilsson J, Feilding A, Nutt DJ et al (2016). LSD-induced entropic brain activity predicts subsequent personality change. Hum Brain Mapp 37: 3203-3213.

Liechti ME, Dolder PC, Schmid Y (2017). Alterations in conciousness and mystical-type experiences after acute LSD in humans. Psychopharmacology (Berl) 234: 1499-1510.

MacLean KA, Johnson MW, Griffiths RR (2011). Mystical experiences occasioned by the hallucinogen psilocybin lead to increases in the personality domain of openness. J Psychopharmacol 25: 1453-1461.

Marona-Lewicka D, Nichols DE (2007). Further evidence that the delayed temporal dopaminergic effects of LSD are mediated by a mechanism different than the first temporal phase of action. Pharmacol Biochem Behav 87: 453-461.

Mueller F, Lenz C, Dolder PC, Harder S, Schmid Y, Lang UE et al (2017a). Acute effects of LSD on amygdala activity during processing of fearful stimuli in healthy subjects. Transl Psychiatry 7: e1084.

Mueller F, Lenz C, Dolder PC, Lang UE, Schmidt A, Liechti ME et al (2017b). Increased thalamic resting state connectivity as a core driver of LSD-induced hallucinations. (submitted).

Muthukumaraswamy SD, Carhart-Harris RL, Moran RJ, Brookes MJ, Williams TM, Errtizoe D et al (2013). Broadband cortical desynchronization underlies the human psychedelic state. J Neurosci 33: 15171-15183.

Nichols DE (2004). Hallucinogens. Pharmacol Ther 101: 131-181. Nichols DE (2016). Psychedelics. Pharmacol Rev 68: 264-355.
Nichols DE, Johnson MW, Nichols CD (2017). Psychedelics as medicines: an emerging new paradigm. Clin Pharmacol Ther 101: 209-219.

Nutt D (2016). Psilocybin for anxiety and depression in cancer care? Lessons from the past and prospects for the future. J Psychopharmacol 30: 1163-1164.

Osorio FL, Sanches RF, Macedo LR, dos Santos RG, Maia-deOliveira JP, Wichert-Ana L et al (2015). Antidepressant effects of a single dose of ayahuasca in patients with recurrent depression: a preliminary report. Rev Bras Psiquiatr 37: 13-20.

Pahnke WN, Kurland AA, Goodman LE, Richards WA (1969). LSD-assisted psychotherapy with terminal cancer patients. Curr Psychiatr Ther 9: 144-152.

Pahnke WN, Kurland AA, Unger S, Savage C, Grof S (1970). The experimental use of psychedelic (LSD) psychotherapy. JAMA 212: $1856-1863$.

Passie T, Halpern JH, Stichtenoth DO, Emrich HM, Hintzen A (2008). The pharmacology of lysergic acid diethylamide: a review. CNS Neurosci Ther 14: 295-314.

Preller KH, Herdener M, Pokorny T, Planzer A, Kraehenmann R, Stämpfli $\mathrm{P}$ et al (2017). The fabric of meaning and subjective effects in LSD-induced states depend on serotonin $2 \mathrm{~A}$ receptor activation. Curr Biol 27: 451-457.

Preller KH, Pokorny T, Krähenmann R, Dziobek I, Stämpfli P, Vollenweider FX (2015). The effect of 5-HT2A/1a agonist treatment on social cognition, empathy, and social decisionmaking. Eur Psychiatry 30(Supp 1): 22.

Preller KH, Vollenweider FX (2016). Phenomenology, structure, and dynamic of psychedelic states. Curr Top Behav Neurosci 6: 451-457.

Riba J, Anderer P, Morte A, Urbano G, Jane F, Saletu B et al (2002). Topographic pharmaco-EEG mapping of the effects of the South American psychoactive beverage ayahuasca in healthy volunteers. Br J Clin Pharmacol 53: 613-628.

Rickli A, Luethi D, Reinisch J, Buchy D, Hoener MC, Liechti ME (2015). Receptor interaction profiles of novel N-2-methoxybenzyl (NBOMe) derivatives of 2,5-dimethoxy-substituted phenethylamines (2C drugs). Neuropharmacology 99: 546-553.

Rickli A, Moning OD, Hoener MC, Liechti ME (2016). Receptor interaction profiles of novel psychoactive tryptamines compared with classic hallucinogens. Eur Neuropsychopharmacol 26: 1327-1337.

Roseman L, Leech R, Feilding A, Nutt DJ, Carhart-Harris RL (2014). The effects of psilocybin and MDMA on between-network resting state functional connectivity in healthy volunteers. Front Hum Neurosci 8: 204.

Roseman L, Sereno MI, Leech R, Kaelen M, Orban C, McGonigle J et al (2016). LSD alters eyes-closed functional connectivity within the early visual cortex in a retinotopic fashion. Hum Brain Mapp 37: 3031-3040.

Ross S, Bossis A, Guss J, Agin-Liebes G, Malone T, Cohen B et al (2016). Rapid and sustained symptom reduction following psilocybin treatment for anxiety and depression in patients with life-threatening cancer: a randomized controlled trial. J Psychopharmacol 30: 1165-1180.

Rucker JJ, Jelen LA, Flynn S, Frowde KD, Young AH (2016). Psychedelics in the treatment of unipolar mood disorders: a systematic review. J Psychopharmacol 30: 1220-1229.

Schindler EA, Gottschalk CH, Weil MJ, Shapiro RE, Wright DA, Sewell RA (2015). Indoleamine hallucinogens in cluster headache: results of the clusterbusters medication use survey. J Psychoactive Drugs 47: 372-381.

Schmid Y, Enzler F, Gasser P, Grouzmann E, Preller KH, Vollenweider FX et al (2015). Acute effects of lysergic acid diethylamide in healthy subjects. Biol Psychiatry 78: 544-553.

Schmidt A, Müller F, Lenz C, Dolder PC, Schmid Y, Zanchi D et al (2017). Acute LSD effects on response inhibition neuronal networks in healthy subjects. (submitted and under review). 
Seibert J, Hysek CM, Penno CA, Schmid Y, Kratschmar DV, Liechti ME et al (2014). Acute effects of 3,4-methylenedioxymethamphetamine and methylphenidate on circulating steroid levels in healthy subjects. Neuroendocrinology 100: 17-25.

Sheehan DV (1972). Review of the use of LSD for the patient near death. Psychiatric Forum 3: 21-23.

Simmler LD, Buchy D, Chaboz S, Hoener MC, Liechti ME (2016). In vitro characterization of psychoactive substances at rat, mouse, and human trace amine-associated receptor 1. J Pharmacol Exp Ther 357: 134-144.

Speth J, Speth C, Kaelen M, Schloerscheidt AM, Feilding A, Nutt DJ et al (2016). Decreased mental time travel to the past correlates with default-mode network disintegration under lysergic acid diethylamide. J Psychopharmacol 30: 344-353.

Steuer AE, Poetzsch M, Stock L, Eisenbeiss L, Schmid Y, Liechti ME et al (2016). Development and validation of an ultra-fast and sensitive microflow liquid chromatography-tandem mass spectrometry (MFLC-MS/MS) method for quantification of LSD and its metabolites in plasma and application to a controlled LSD administration study in humans. Drug Test Anal (e-pub ahead of print; doi:10.1002/dta.2042).

Strajhar P, Schmid Y, Liakoni E, Dolder PC, Rentsch KM, Kratschmar DV et al (2016). Acute effects of lysergic acid diethylamide on circulating steroid levels in healthy subjects. J Neuroendocrinol 28: 12374.

Strassman RJ, Qualls CR (1994a). Dose-response study of N, $\mathrm{N}$-dimethyltryptamine in humans: I. Neuroendocrine, autonomic, and cardiovascular effects. Arch Gen Psychiatry 51: 85-97.

Strassman RJ, Qualls CR, Uhlenhuth EH, Kellner R (1994b). Dose-response study of N,N-dimethyltryptamine in humans: II. Subjective effects and preliminary results of a new rating scale. Arch Gen Psychiatry 51: 98-108.

Studerus E, Kometer M, Hasler F, Vollenweider FX (2011). Acute, subacute and long-term subjective effects of psilocybin in healthy humans: a pooled analysis of experimental studies. J Psychopharmacol 25: 1434-1452.

Tagliazucchi E, Roseman L, Kaelen M, Orban C, Muthukumaraswamy SD, Murphy $\mathrm{K}$ et al (2016). Increased global functional connectivity correlates with LSD-induced ego dissolution. Curr Biol 26: 1043-1050.

Terhune DB, Luke DP, Kaelen M, Bolstridge M, Feilding A, Nutt D et al (2016). A placebo-controlled investigation of synaesthesialike experiences under LSD. Neuropsychologia 88: 28-34.

Vollenweider FX, Leenders KL, Scharfetter C, Maguire P, Stadelmann O, Angst J (1997). Positron emission tomography and fluorodeoxyglucose studies of metabolic hyperfrontality and psychopathology in the psilocybin model of psychosis. Neuropsychopharmacology 16: 357-372.

Vollenweider FX, Vollenweider-Scherpenhuyzen MF, Babler A, Vogel H, Hell D (1998). Psilocybin induces schizophrenia-like psychosis in humans via a serotonin-2 agonist action. Neuroreport 9: 3897-3902.

Wolbach AB Jr, Miner EJ, Isbell H (1962). Comparison of psilocin with psilocybin, mescaline and LSD-25. Psychopharmacologia 3: 219-223.

cc)(1) (2) This work is licensed under a Creative Commons Attribution-NonCommercial-ShareAlike $\quad 4.0$ International License. The images or other third party material in this article are included in the article's Creative Commons license, unless indicated otherwise in the credit line; if the material is not included under the Creative Commons license, users will need to obtain permission from the license holder to reproduce the material. To view a copy of this license, visit http://creativecommons.org/licenses/by-nc-sa/4.0/

(C) The Author(s) 2017 